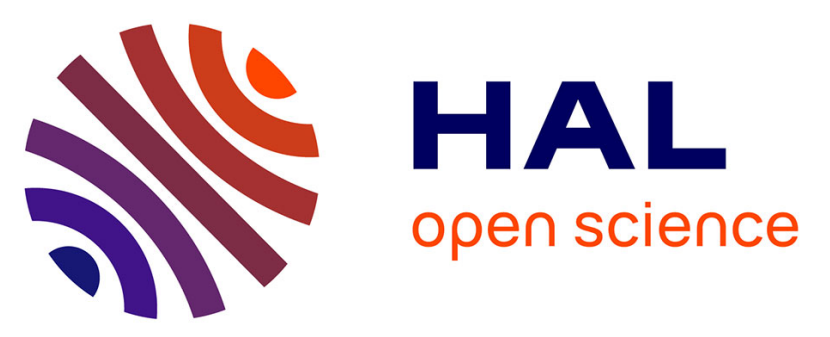

\title{
Improvement of Varioptic's liquid lens based on electrowetting: how to obtain a short response time and its application in the design of a high resolution iris biometric system
}

Benjamin Burger, Serge Meimon, Cyril Petit, M.C. Nguyen

\section{To cite this version:}

Benjamin Burger, Serge Meimon, Cyril Petit, M.C. Nguyen. Improvement of Varioptic's liquid lens based on electrowetting: how to obtain a short response time and its application in the design of a high resolution iris biometric system. Proceedings of SPIE, the International Society for Optical Engineering, 2015, 9375, pp.93750S-1-9. 10.1117/12.2075719 . hal-01429711

\author{
HAL Id: hal-01429711 \\ https://hal.science/hal-01429711
}

Submitted on 4 Oct 2021

HAL is a multi-disciplinary open access archive for the deposit and dissemination of scientific research documents, whether they are published or not. The documents may come from teaching and research institutions in France or abroad, or from public or private research centers.
L'archive ouverte pluridisciplinaire HAL, est destinée au dépôt et à la diffusion de documents scientifiques de niveau recherche, publiés ou non, émanant des établissements d'enseignement et de recherche français ou étrangers, des laboratoires publics ou privés. 


\title{
Improvement of Varioptic's liquid lens based on electrowetting: how to obtain a short response time and its application in the design of a high resolution iris biometric system
}

\author{
Benjamin Burger ${ }^{\mathrm{a}}$, Serge C. Meimon ${ }^{\mathrm{b}}$, Cyril Petit ${ }^{\mathrm{b}}$, Minh Chau Nguyen ${ }^{\mathrm{a}}$ \\ ${ }^{a}$ Varioptic, a Business Unit of Parrot S.A., 24 B rue Jean Baldassini, 69007 Lyon (France); ${ }^{b}$ \\ Département d'optique théorique et appliquée, Unité haute résolution angulaire, ONERA, 29 \\ Av. de la Division Leclerc, 92322 Chatillon cedex, France
}

\begin{abstract}
This communication presents the results obtained for decreasing the response time of electrowetting-based real time focus correctors (liquid lenses). In order to provide a compact iris biometric system demonstrator, we have achieved a response time at $90 \%$ of $7.5 \mathrm{~ms}$ for a change in focalization from 0 diopter to 10 diopter with a liquid lens having an aperture of $1.9 \mathrm{~mm}$. We have used a hydrodynamic fluid reorganization model to predict the features of these fast liquid lenses and evaluated the sensivity of the response time to the different conception parameters.
\end{abstract}

Keywords : liquid lens, response time, biometry, autofocus, electrowetting, electro-optical, iris, command law

\section{INTRODUCTION}

The security of materials, information and people is one of the great challenges the society has to face. To improve the security, one of the solutions considered is a fast development of biometric recognition: it would ensure the protection of owner's data or the identification of dangerous persons.

The two most efficient biometrics are the fingerprint and the iris biometry. Since the fingerprint biometry can be biased in the case of manual workers, whose fingers pattern are likely to be damaged due to their profession, the iris biometry is very likely to become the privileged biometric technology in the future. However, the development of iris biometry is for the moment limited, due to the difficulty to acquire a properly resolved image with a compact biometric device. It is commonly admitted that proper iris recognition needs 100 to 200 pixels in an iris diameter, meaning a resolution of 50 to $100 \mu \mathrm{m} .[1,2]$

The aim of the project IRISEM, supported by the French ANR, is to identify and mitigate the technical challenges for the development of compact, low cost, adaptive optics for the iris biometry. In this paper, we present why the project needed a fast, narrow angle, autofocus component and how such a component is achievable. 


\section{OPTICAL DESIGN OF THE DEVICE}

The specifications of the device are:

- The object is expected in a volume of $10 \mathrm{~cm}$ (height) $\mathrm{x} 10 \mathrm{~cm}$ (width) $\mathrm{x} 1 \mathrm{~cm}$ (field depth). A first stage of optical tracking is used to place the acquisition volume at the good place.

- The acquisition is realized at $60 \mathrm{~cm}$ of the optical device.

- The image field targeted will have dimensions of $1,8 \mathrm{~cm}$ (vertical) x 2,4 cm (horizontal).

- The pixel size is $60 \times 60 \mu \mathrm{m}$ maximum on the eye.

- The size of the image is $1000 \times 1000$ pixel

- $\quad$ The exposure time is $100 \mathrm{~ms}$

- A control loop is used to follow the micro-moves of the eye during the exposure time. The frequency of this control loop is $250 \mathrm{~Hz}$

- A fast mirror is used to follow the eyes movements in $\mathrm{x}$ and $\mathrm{y}$

- A fast autofocus liquid lens is used to target the image field.

- The image is obtained in the infra-red spectrum (between 700 and $900 \mathrm{~nm}$ ), according to the ISO 19794-6 standard. For a good recognition performance, 250 pixels are required on the IRIS diameter.

Based on the specification of the iris image acquisition device, the specifications of the liquid lens are:

- Useful aperture : $2 \mathrm{~mm}$

- Focalization range : $-5 \mathrm{D} /+15 \mathrm{D}$

- Wave-front error (WFE) RMS on the useful aperture : $60 \mathrm{~nm}$ maximum

- Response time : 10 ms maximum

- Criteria for the response time: the change in focalization is at least $90 \%$ of the change required and the instant WFE RMS is less than the quasi-static WFE $+50 \mathrm{~nm}$.

- The operating temperature is $20 \pm 10^{\circ} \mathrm{C}$.

\section{KEY PARAMETERS FOR THE SPEED OPTIMIZATION OF THE LIQUID LENS}

The first step for the conception of a fast autofocus liquid lens is the determination of the parameters which could influence the response time. These parameters are listed in the following scheme (refer to [3] for more details). 


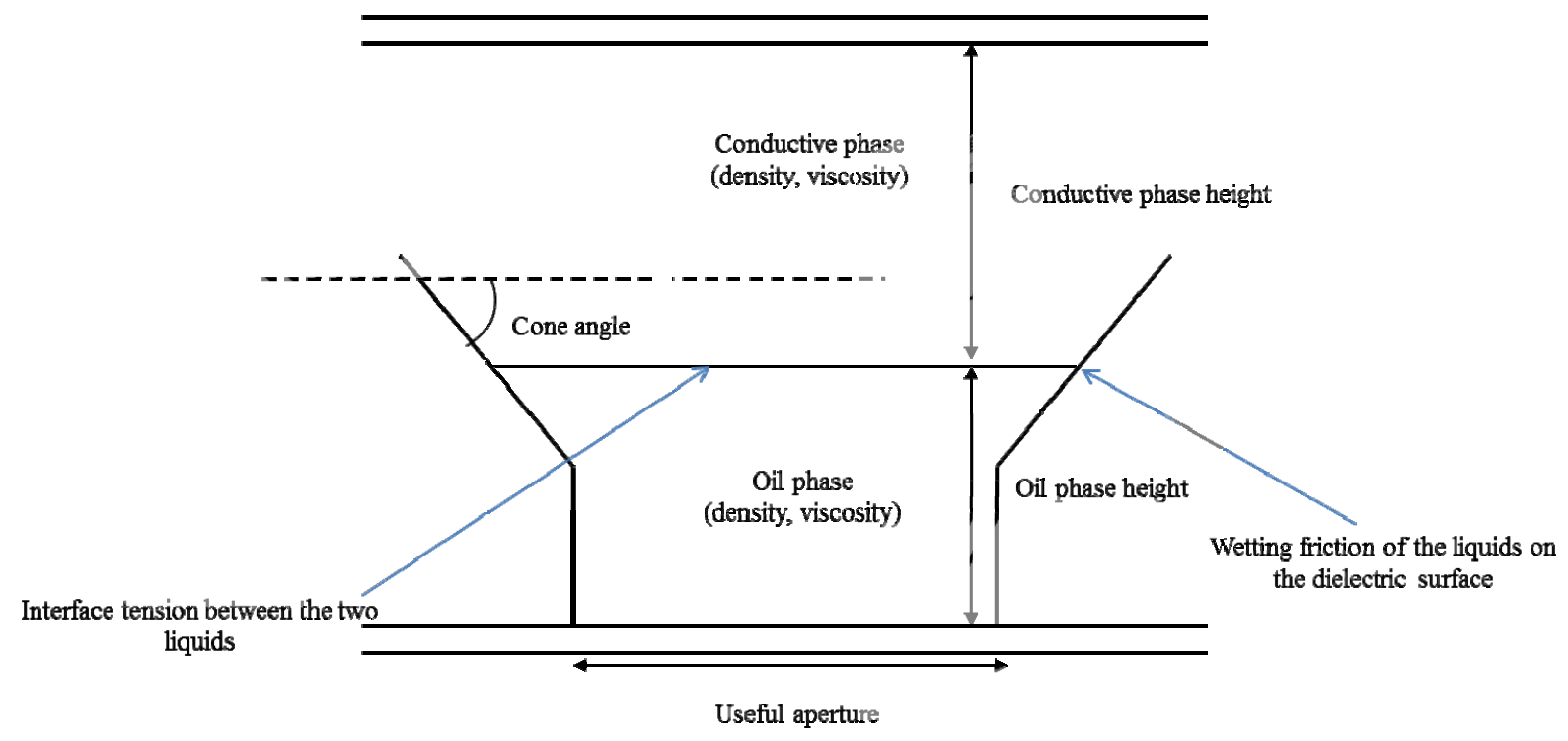

Figure $1:$ schematic view of a liquid lens

We chose to organize these parameters in three categories:

- Geometrical parameters (useful aperture, cone angle, height of each liquid phase)

- Physico-chemical parameters (density and viscosity of each liquid phase, interface tension between the two liquids, wetting forces between the liquids and the dielectric surface)

- Command law

In B. Berge precedent work on the liquid lens,[4] a hydrodynamic model has been defined in order to predict the response time of the liquid lens. In this ideal model (no friction between of the liquids on the dielectric surface when the focalization of the lens is changing), the response time of the liquid lens is determined by :

- The aperture of the liquid lens

- The viscosities of the liquids

- The dimensions of the cell

- The density of the liquids

- The interface tension between the two liquids.

A numerical simulation was used, and a good agreement was found between the experimental response time of the liquid lenses Baltic 617 and Arctic 316 and the predicted values.

When we simulated the response time of the liquid lens with the geometric parameters required for the iris biometry (useful aperture: $2 \mathrm{~mm}$, thickness of the liquid layers: $0,6 \mathrm{~mm}$ each), we found the following results:

- In this geometry, the liquid's flow is not limited by the viscosity when it is in the range of the typical liquid lens liquids (conductive phase: viscosity lower than $5 \mathrm{cSt}$, oil phase: viscosity lower than 2.5 $\mathrm{cSt}$ ).

- The speed of the liquid lens is highly dependent upon the interface tension between the two liquids.

- The speed of the liquid lens is highly dependent upon the useful aperture of the liquid lens.

Therefore we have chosen the following tunable parameters to optimize the response time of the liquid lens: 
- $\quad$ Useful aperture of the lens

- Interface tension between the two liquids

- Optimization of the command law (in order to find the critical damping of the oscillating system)

Due to the non-ideality of the flow (some friction is expected when the liquids move on the dielectric surface), we have added two parameters:

- Surface energy of the dielectric material

- Inclination of the conic surface on which the liquids are moving. This parameter determines geometrically the contact angle range of the electrowetting phenomenon for a liquid lens focalizing between -5 to 15 diopter.

We have then studied experimentally the variation of the response time of the liquid lens when tuning these parameters.

\section{VARIATION OF THE RESPONSE TIME TO THE USEFUL APERTURE OF THE LENS}

We have first studied the relation between the response time of the lens and its mechanical aperture. For these experiments, a $1 \mathrm{kHz}$ square voltage was applied to the liquid lenses. The voltage applied to the lenses was adjusted in order to change its optical power from 0 diopter to 1 diopter, 0 diopter to 4 diopters, or 0 diopter to 10 diopters. The voltage command is a single step. The optical power measurement is realized with a HASO Shack-Hartman wave front analyzer form Imagine Optic, France. The measurement is performed on a pupil with a diameter of $1.3 \mathrm{~mm}$. The liquids used for this experiment are the liquids of the commercial lens Arctic 316, with an interface tension of $16.0 \pm 0.2 \mathrm{mN} / \mathrm{m}$ at $20^{\circ} \mathrm{C}$.

\begin{tabular}{|c|c|c|c|}
\hline Mechanical aperture & RT for 0D to 1D & RT for 0D to 4D & RT for 0D to 10D \\
\hline $\mathbf{2 . 1} \mathbf{~ m m}$ & $136 \mathrm{~ms}$ & $60 \mathrm{~ms}$ & $24 \mathrm{~ms}$ \\
\hline $\mathbf{1 . 8} \mathbf{~ m m}$ & $105 \mathrm{~ms}$ & $70 \mathrm{~ms}$ & $30 \mathrm{~ms}$ \\
\hline $\mathbf{1 . 6} \mathbf{~ m m}$ & $95 \mathrm{~ms}$ & $50 \mathrm{~ms}$ & $25 \mathrm{~ms}$ \\
\hline
\end{tabular}

Table 1 : dependence of the response time to the useful aperture of the liquid lens

These results have shown a decrease of the response time with the decrease of the mechanical aperture for the small focus changes (1D or less), but the correlation between aperture and speed of the lens is less evident for larger focus steps.

\section{VARIATION OF THE RESPONSE TIME WITH THE INTERFACE TENSION OF THE LIQUIDS}

In second, we studied the relation between the response time of the lens and the interface tension of the liquids. The same $1 \mathrm{kHz}$ square voltage, adjustment of the voltage to the optical power required and single step command are used as previously.

The package of the liquid lens has a mechanical aperture of $2.7 \mathrm{~mm}$ and the measurements are made on a pupil of $2.6 \mathrm{~mm}$. 


\begin{tabular}{|l|c|c|c|}
\hline Interface tension & RT for 0D to 1D & RT for 0D to 4D & RT for 0D to 10D \\
\hline $\mathbf{1 6} \mathbf{~ m N / m}$ & $134 \mathrm{~ms}$ & $94 \mathrm{~ms}$ & $58 \mathrm{~ms}$ \\
\hline $\mathbf{2 2} \mathbf{~} \mathbf{N} / \mathbf{m}$ & $80 \mathrm{~ms}$ & $40 \mathrm{~ms}$ \\
\hline $\mathbf{3 0} \mathbf{~} \mathbf{N} / \mathbf{m}$ & $18 \mathrm{~ms}$ & $18 \mathrm{~ms}$ & $9 \mathrm{~ms}$ \\
\hline
\end{tabular}

Table 2 : dependence of the response time to liquid/liquid interface tension

With these results, we see a strong variation of the response time with the surface tension between the oil and the conductive phase, in good agreement with the hydrodynamic model.

\section{VARIATION OF THE RESPONSE TIME WITH THE CONE ANGLE}

In third, we have studied the relation between the response time of the lens and the cone angle used for the design of the liquid lens. The same $1 \mathrm{kHz}$ square voltage, adjustment of the voltage to the optical power required and single step command are used as previously. The mechanical aperture of the lens is $2.1 \mathrm{~mm}$, the measurements are made on a pupil of $1.3 \mathrm{~mm}$ and the interface tension between the two liquids is $16 \mathrm{mN} / \mathrm{m}$.

\begin{tabular}{|l|c|c|c|}
\hline \multicolumn{1}{|c|}{ Cône angle } & RT for 0D to 1D & RT for 0D to 4D & RT for 0D to 10D \\
\hline $\mathbf{5 5}^{\circ}$ & $136 \mathrm{~ms}$ & $60 \mathrm{~ms}$ & $24 \mathrm{~ms}$ \\
\hline $\mathbf{4 5}^{\circ}$ & $255 \mathrm{~ms}$ & $145 \mathrm{~ms} \mathrm{~ms}$ \\
\hline $\mathbf{3 0}^{\circ}$ & $620 \mathrm{~ms}$ & $300 \mathrm{~ms}$ & $130 \mathrm{~ms}$ \\
\hline
\end{tabular}

Table 3 : dependence of the response time to cone angle of the liquid lens

With these results, we see a very variation of the response time with the cone angle used for the design of the liquid lens. Our explanation is as follow: according to the literature, electrowetting hysteresis is related to friction of the liquids at the triple (oil, conductive phase, dielectric) interface.[5] Previous work of M. Maillard showed that electrowetting hysteresis is higher at lower contact angle.[6] A direct consequence of these two statements is: increasing the cone angle will increase the contact angle at 0 diopter, therefor it will decrease electrowetting hysteresis and friction. With a lower friction, the liquid lenses will be faster. This observation enforces the hypothesis of friction limiting the speed of the liquid lens.

\section{VARIATION OF THE RESPONSE TIME WITH THE WETTING OF THE LIQUIDS}

In fourth, we have studied the relation between the response time of the lens and the wetting of the liquids on the dielectric surface. The same $1 \mathrm{kHz}$ square voltage, adjustment of the voltage to the optical power required and single step command are used as previously. The mechanical aperture of the lens is $2.7 \mathrm{~mm}$, the measurements are made on a pupil of $2.6 \mathrm{~mm}$, the interface tension between the two liquids is $28 \mathrm{mN} / \mathrm{m}$ (same liquids for the two batches of liquid lenses), the cone angle is $45^{\circ}$. The same liquids were used for the two experiments, and the natural contact angle of the liquids on the surface is lower than $10^{\circ}$. The hysteresis is negligible for the two configurations, as expected from the contact angle value.[6] 


\begin{tabular}{|l|c|c|c|}
\hline Topcoat surface energy & RT for 0D to 1D & RT for 0D to 4D & RT for 0D to 10D \\
\hline $\mathbf{4 3} \mathbf{~} \mathbf{N} / \mathbf{m}$ & $45 \mathrm{~ms}$ & $22.5 \mathrm{~ms}$ & $10 \mathrm{~ms}$ \\
\hline $\mathbf{2 4} \mathbf{~} \mathbf{N} / \mathbf{m}$ & $32.5 \mathrm{~ms}$ & $22.5 \mathrm{~ms} \mathrm{~ms}$ \\
\hline
\end{tabular}

Table 4 : variation of the response time with the dielectric surface energy

In these results, the variation of the response time value with the surface energy of the coating is not very significant. However, the shape of the focus response as a function of the time may be very different, even when the calculated response time value is the same.

For example, the normalized responses curves for the step of 10 diopters are:

\section{OD to $10 \mathrm{D}$ normalized response}

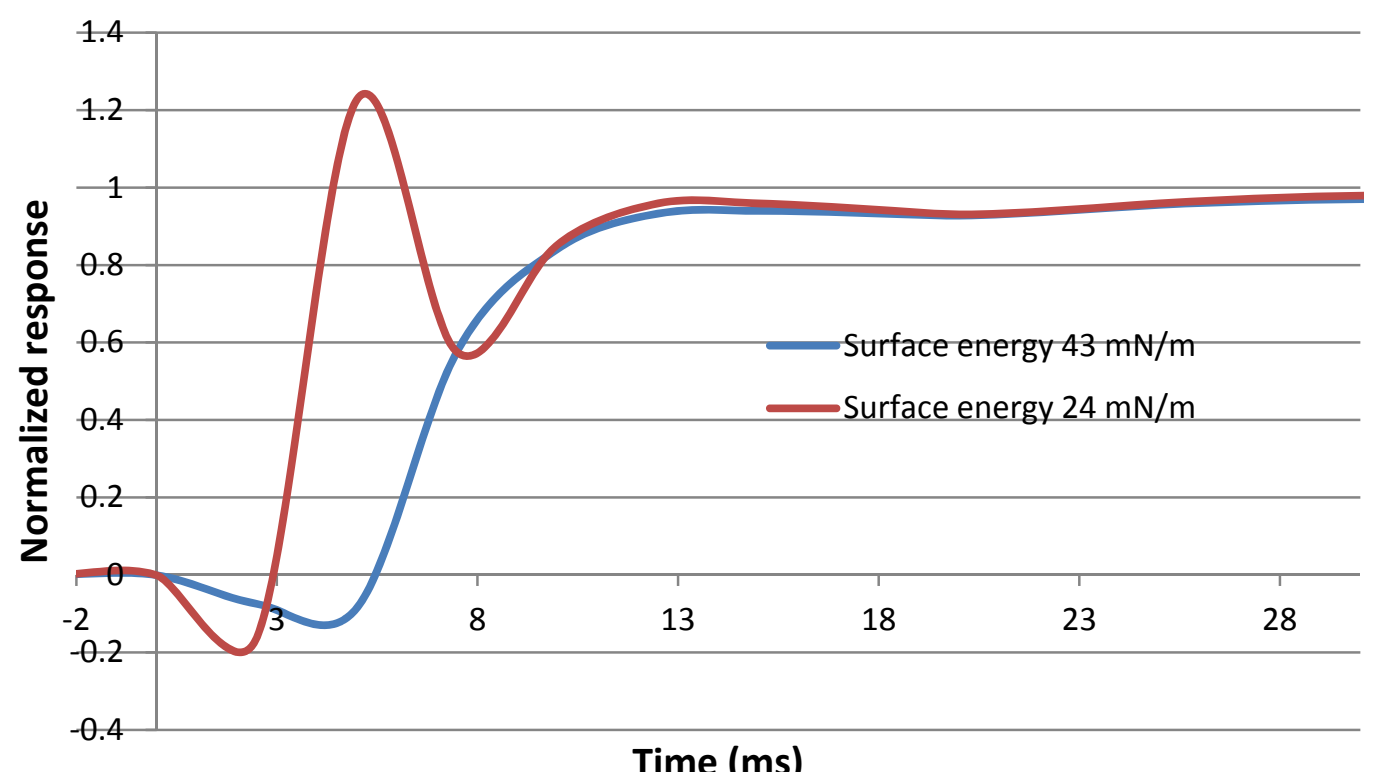

Figure 2 : normalized focus response as a function of time for two different surface energies. The focus variation is 10 diopter.

In conclusion, even if the measured response time between the batches of lenses is similar, the local slope of the response curve is higher when the surface energy of the dielectric is lower. It means the intrinsic speed of the device is higher for low surface energies.

We have not rigorously explained and modeled this effect, but we can explain this observation with an "adhesion" force between the liquid and the solid surface. When the surface has a low surface energy, the interactions between the liquids and the surface are minimum, there is no friction of the liquids on the surface. For higher surface energies, some friction appears between the liquids and the surface, making the response slower. 


\section{OPTIMIZATION OF THE COMMAND LAW}

As exposed in B. Berge's paper,[4] the classical response of a liquid lens to a step command is a second order oscillator. We will consider the damping constant $\varepsilon$ of this oscillator. Typically, the response time of the liquid lens Arctic 316 presented by Berge has $\varepsilon<1$ (overdamped system). It is easy to accelerate this liquid lens by applying an overshoot of the step command. On the other side, for liquid lenses like the Baltic 617, the lenses maybe underdamped. This issue is particularly critical for the fast liquid lenses developed according to the preceding paragraphs, where we increased the stiffness of the liquid-liquid interface, the operating voltage of the step and decreased the friction between the liquids and the solid surface. Then, we needed a command law in order to accelerate underdamped systems.

Considering the following equation of a second order oscillator defined by the liquid lens :

$1 / \omega_{0}^{2} \ddot{e}+2 \varepsilon / \omega_{0} \dot{e}+e=v(t)$

where $\omega_{0}$ is the natural pulsation of the oscillator, $\varepsilon$ is the damping factor, $v(t)$ the voltage applied to the liquid lens, e(t) the optical power of the liquid lens.

We used the Laplace transform and converted this expression in:

$\left(1+2 \varepsilon p / \omega_{0}+\left(\mathrm{p} / \omega_{0}\right)^{2}\right) \mathrm{E}(\mathrm{p})=\mathrm{V}(\mathrm{p})$

where $\mathrm{E}(\mathrm{p})$ and $\mathrm{V}(\mathrm{p})$ are, respectively, the Laplace transforms of the signals $\mathrm{v}(\mathrm{t})$ and $\mathrm{e}(\mathrm{t})$ with the variable $\mathrm{p}$.

The transfer function $\mathrm{H}(\mathrm{p})=\mathrm{E}(\mathrm{p}) / \mathrm{V}(\mathrm{p})$ of this system is :

$\mathrm{H}(\mathrm{p})=1 /\left(1+2 \varepsilon \mathrm{p} / \omega_{0}+\left(\mathrm{p} / \omega_{0}\right)^{2}\right)$

We then used a matlab simulation of this transfer function to analytically determine the stimulation producing the following response curve of the liquid lens:

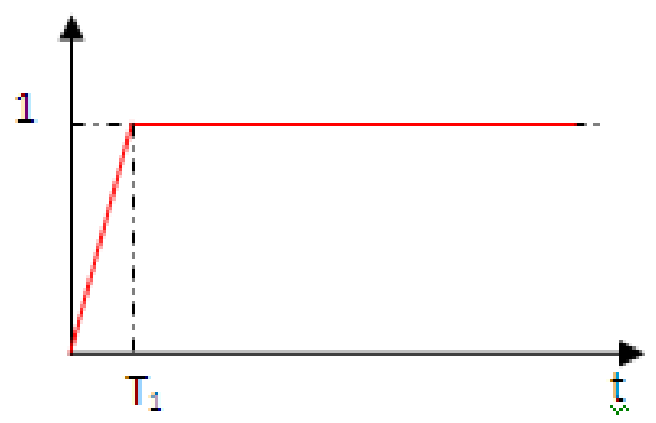

Figure 3 : shape of the variation of the focus with time wanted

The result of this simulation issued the following shape for the optimal command law. The parameters of this command low are : V1, V2, and the slope. The values of Vi and Vf are determined by the electro-optical characteristics of the liquid lens. 


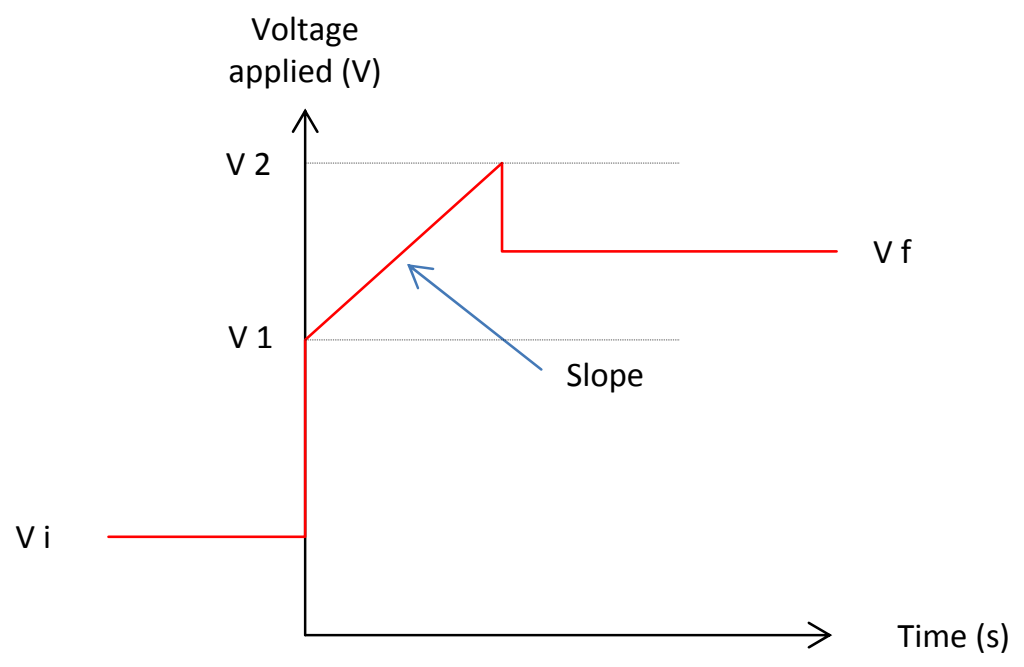

Figure 4 : shape of the driving voltage used

When using the optimized command, the following results were obtained. The mechanical aperture of the lens is $2.0 \mathrm{~mm}$, the measurements are made on a pupil of $1.9 \mathrm{~mm}$, the interface tension between the two liquids is 31 $\mathrm{mN} / \mathrm{m}$, the cone angle is $55^{\circ}$. The step of focus is from $0 \mathrm{D}$ to $10 \mathrm{D}$.

\begin{tabular}{|c|c|c|c|}
\hline$(\mathrm{V} 1-\mathrm{Vi}) /(\mathrm{Vf}-\mathrm{Vi})$ & $(\mathrm{V} 2-\mathrm{Vf}) /(\mathrm{Vf}-\mathrm{Vi})$ & Response time $(\mathrm{ms})$ \\
\hline \multicolumn{3}{||}{ Command : single step } & 15 \\
\hline 0.4 & 0 & 1.3 & 12.5 \\
\hline 0.6 & 0 & 1.25 & 7.5 \\
\hline 0.6 & 0 & 0.5 & 17.5 \\
\hline
\end{tabular}

Table 5 : parameters of the driving voltage functions used. and the response time obtained. Sampling of the command : $1 \mathrm{~ms}$. Sampling of the detection : $2.5 \mathrm{~ms}$

This optimized command law proved effective for the optimization of the response time of the liquid lens.

\section{CONCLUSION}

In conclusion, we confirmed the dependence of the response time to the liquid-liquid interface tension predicted by Berge's model.[4] This model relies on "ideal" conditions where the friction phenomena are neglected. In his paper, Berge effectively established that some friction occurs and the damping measured is higher than the damping predicted for an ideal liquid lens.

We have proposed in this study a liquid lens design with an optimized response time of $7.5 \mathrm{~ms}$ at $90 \%$ for a change in focalization from 0 diopter to 10 diopter with an aperture of $1.9 \mathrm{~mm}$. We have minimized the slowdown of the lens attributed to friction. The best design against friction is: a low surface energy dielectric (under $25 \mathrm{mN} / \mathrm{m}$ ) and a cone angle of at least $55^{\circ}$.

Finally, when the critical damping is not achieved, we recommend a design of fast liquid lenses where the oscillating response is underdamped and we add the adequate damping with a specific command law. 


\section{ACKNOWLEDGEMENTS}

The authors would like to thank the French national agency for research for its financial support, and the partner of the IRISEM project: the ONERA, Telecom Sud Paris and Morpho.

The authors thank also Eric Simon, Bruno Berge, Géraldine Malet, Stéphanie Chevalliot, Florent Thieblement and Nelly Garcia for their advice and useful technical discussion.

And the authors thank the pilot production team of Varioptic for their support in the production of the liquid lenses.

\section{REFERENCES}

[1] Daugman, J. and Downing, C., "Epigenetic randomness, complexity, and singularity of human iris patterns," Proceedings of the Royal Society B Biological Sciences, 268, 1737 (2001)

[2] Daugman, J. "Probing the uniqueness and randomness of IrisCodes: Results from 200 billion iris pair comparisons," Proceedings of the IEEE, 94, 1927 (2006)

[3] Simon, E., Berge, B., Fillit, F., Gaton, H., Guillet, M., Jacques-Sermet, O., Laune, F., Legrand, J., Maillard, M., Tallardon, N., "Optical design rules of a camera module with a liquid lens and principle of command for AF and OIS functions," Proc. SPIE 7849, 784903 (2010)

[4] Berge, B., Broutin, J., Gaton, H., Malet, G., Simon, E. and Thieblemont, F., "Liquid lens based on Electrowetting: actual developments on larger aperture and multiple electrodes design for image stabilization or beam steering," Proc. SPIE 8616, 861601 (2013)

[5] Li, F. and Mugele, F., "How to make sticky surfaces slippery: Contact angle hysteresis in electrowetting with alternating voltage," Appl. Phys. Lett. 92, 244108 (2008)

[6] Maillard, M., Legrand, J. and Berge, B., "Two Liquids Wetting and Low Hysteresis Electrowetting on Dielectric Applications," Langmuir 25, 6162 (2009) 